\title{
Investigation Methods of Mountain Torrent Disaster in Wulian County of Shandong Province
}

\author{
Guoqing Sang ${ }^{1, a^{*}}, \mathrm{Hao} \mathrm{Xu}^{1, \mathrm{~b}}$ and Cuiling $\mathrm{JiaO}^{2, \mathrm{c}}$ \\ ${ }^{1}$ University of Jinan School of Resources and Environmental Sciences, Jinan 250012, China \\ ${ }^{2}$ East Part of South to North Water Diversion in Shandong CO. LTD, Jinan 250013, China \\ àsangguoqing@163.com, b24340893@qq.com, ${ }^{\mathrm{c}} 26994016 @ q q . c o m$
}

\begin{abstract}
Keywords: Torrential flood disaster; Investigation and evaluation; Dangerous areas
\end{abstract}
\begin{abstract}
Mountain flood disaster investigation and evaluation is the essential work of mountain flood disaster prevention.It is also an important guarantee and basic support of flash flood forecast and warning. Wulian County of Shandong province is one of the prevention and control areas in " National flood disaster prevention planning ", and the first batch of pilot counties on investigating and assessing torrential flood disaster in Shandong. Taking the typical small watershed of Wulian County as an example, the investigation and evaluation method of mountain torrent disaster is expounded. The results of mountain flood disaster investigation are given. Based on the work flow of mountain torrent disaster investigation and evaluation, the basic situation of typical small watershed - Wulian County-Panlong River watershed, the preliminary results of investigation of typical villages along the river are given, and the main field investigation of mountain torrent disaster is analyzed. Experience and existing problems provide reference for other areas of mountain torrents .
\end{abstract}

\section{Introduction}

The survey and evaluation of torrential disasters in Shandong Province from 2013 to 2015 involved 12 cities, 56 counties (cities and districts) and mountain flood disaster prevention and control areas $49,000 \mathrm{~km} \mathrm{2}$. Wulian County is not only a key control area in the "national flash flood disaster prevention planning", but also the flash flood disaster investigation and evaluation of the first batch of pilot counties in Shandong Province. Wulian county is located in the southwest of the Shandong Peninsula, east of the Yellow Sea. Mountain and hilly accounted for $86 \%$, the total topography of the central high, north-south low, the average elevation of about $178.00 \mathrm{~m}$. Wulian county is located in warm temperate semi humid monsoon climate zone. The average annual rainfall is $735.8 \mathrm{~mm}$, the spatial and temporal distribution of precipitation is uneven and the flood season concentrated enormously. The main rivers in the territory are Chaobai River, Street River, Yuan River, Hong Ning River and Sanyang River. There are 21 rivers totally. The source is shallow and the main stream is steep. A total of 815 reservoirs and ponds; a total capacity is 224 million 882 thousand meters, including 6 medium-sized reservoirs and 156 small reservoirs.Due to the special mountain terrain, river characteristics and rainfall characteristics, mountain torrents disaster in Wulian occurred frequently, which not only causes damage to the infrastructure in the hilly area, but also poses great harm and threat to people's life and property security. Historically, it occurred serious torrential flood disaster in 1988, 1989, 1997, 1999, 2008. From 4 to 19 on August 17th, 2008, the county suffered the heavy rain with an average rainfall of $115.6 \mathrm{~mm}$, the maximum rainfall is $209.5 \mathrm{~mm}$. There are 3 dam collapse, 12 check dam collapse, 28 bridges which were washed away and 6, the dam embankment. There are 3 landslides in the county, 12 landslides in Gufang, 28 bridges and culverts, 6 river dams, river banks of 9,000 m, village roads of $34.9 \mathrm{~km}$, farmland of $8,800 \mathrm{~m}$ and 39 collapsed houses. Direct economic losses of more than 500 million yuan the torrential flood occurred during the day and transferred in time, so that it did not cause casualties. In June 2014, under the guidance of the national torrential flood disaster prevention project team, Shandong province in strict accordance with the requirements of the technical requirements for "the investigation of mountain torrents disaster" and "the technical requirements for the analysis and evaluation of mountain torrents disaster", Kouguan Zhen taking small watershed as a basic 
unit of work organization carried out investigation and evaluation of flood disaster survey provincial pilot work in Wulian County.

\section{Survey Process}

Workflow. Mountain torrent disaster investigation and evaluation of the industry survey and field survey interrelated ${ }^{[1-2]}$. The field investigation is not only the confirmation and improvement of the industry investigation, but also the continuation and expansion of the industry investigation. Field surveys must be based on an industry survey. In a certain understanding of the investigation of the case, to obtain a richer professional data through surveys and measurements. . Field investigation can be divided into two parts, survey and measurement ${ }^{[2-4]}$. In principle, In principle, to investigate the main, supplemented by measurement,the two integrated closely . Through primary filling, field visits, on-site survey, engineering survey and other methods to obtain first-hand data. Investigation team consists of water conservancy and hydrological professionals. Each group of 4 to 5 people, is mainly responsible for -site investigation.. Surveying work commissioned by the corresponding qualification of professional surveying and mapping unit, set up a separate measurement group and follow the survey group to carry out measurement related work. . Measurement group carried 2 to 3 sets of RTK instruments, each instrument has 1 to 2 people, including one measuring the risk of homestead elevation, 1 to 2 sets of river cross-section, wading projects, flood marks and so on.

Pre-preparation. Before carrying out field investigation, we should make full preparations. According to the results of the industry survey and the actual situation, the use of work plans and existing drawings, preliminary identificate and investigate detailedly small watersheds, along the river villages, dangerous areas, enterprises and institutions such as directory, in order to field investigation . And township (town) or small watershed as a unit develop an investigation plan in advance to inform the town water station to do a good job with the work of the preparation, and collect the coordinates of the calibration point data. Before the village investigation, the docking with the village head in advance, to collect or draw the village layout plan. That is, including the village households, wading project location, river position and other content of the simple diagram. Then we arrange the village contact person, implement the investigation itinerary and route, the initially divide dangerous areas along the river village.

On-site Investigation Process. Taking small watershed as a unit, select the relevant mountain rivers and do field survey one by one from upstream to downstream along the river in the village ${ }^{[5]}$.

Preliminary and thorough investigation. After entering the village, from the upstream to the downstream, do the preliminary survey on the topography and landform, land use, vegetation cover, agricultural production, upstream flood source, flood capacity, river flood control capacity, water conservancy project status, flood channel and possible submerged area and so on, to obtain the basic situation mountain flood along the river in the village At the same time, shoot village photos and record the survey content and time, in order to post-data collating.

Historical flood survey. We visit the relevant experience of the villagers, multi-verification, to determine the Hong mark. Then we label on-site, take photos, do measurement of the location and elevation of the mark. In addition, attention should be paid to record the project scheduling and damage about the historical flood.

Determine the water level and hazard areas. . Determine the water level disaster in the village, and initially determine the risk zone and transferable routes draw sketches in the field. The delineation standard of the danger zone is generally within 1 meter of the historical flood mark, and the conditions such as upstream and downstream and special working conditions should also be taken into account.

Homestead survey and demographic statistics for buildings in hazardous areas. Homestead measurement work is based on RTK, supplemented by total station. The main progress of measurement constraints is in the GPS signal. At the same time count up the number of people, take pictures of the housing and classify preliminary

Section measurement. There are two choices of cross-section in Wulian County: First, select the relatively straight section of the river, calculate the flow by Manning formula to determine the upper, 
middle and lower section location. Second, select the upstream control structures such as weir, and so on. Measure the geometric characteristics of dams, stacks and other hydraulic structures. At the same time, pay attention to understand the river bed quality, take riverbed photos, to determine river bed roughness.

Investigation of water diversion project and its flood capacity. Investigate on dams, bridges, weirs, culverts and other wading structures affecting the flooding of river courses. At the same time, investigate river history, status quo and water level rise phenomenon. Photographs of the wading project should be able to reflect the relationship between the main body of the project and the surrounding terrain and the size of the main structure of the project. At the same time, measure the location of the wading project and the basic parameters.

\section{Preliminary findings}

\section{A Small Watershed in Wulian County---- the Basic Situation of Panlong River Small Watershed.}

Panlonghe small watershed in Wulian County is located in call-off town, Wulian County, $20 \mathrm{~km}$ east of the county, the watershed Panlong River tributary of the Chaohe River is a two-level river. Watershed export is located in the Panlong River and the mainstream of the Chaohe River interchange, longitude $119.43995^{\circ}$, latitude $35.679767^{\circ}$. There is not reservoir regulation in the upstream, downstream import into the river. Soil texture in the basin is sandy loam, with low forest cover, mostly arable land and cultivated field.

The small watershed consists mainly of 9 villages: Beiping Village, Heizi Village, Baishizi Village, Caijiagou Village, Xiaobigou Village, Xiaodiji Village, Dadi Village, Xiaoshuashu Village and Huashu Village. According to the results of the investigation of mountain torrents, Panlong River watershed flood prevention and control area is 15.98 kilometers, of which 8005 acres of arable land, accounting for $33.3 \%$ of the total area. ; The total population is 3,277 people, 1314 households. 9 villages are along the river village. 9 villages are along the river village which also focus on prevention and control of the area.

Preliminary Results of Investigation of Typical Villages along the River. Historical flood mark survey. According to site visits and the multi-verification, determine that the major historical disasters in the village of Da Ji Village floods is the flood on September 18th, 1998.

Preliminary delineation of dangerous areas and transferring routes. According to the basin topography, ditch distribution, residents living conditions, site survey flood traces, visits to farmers, we determine the water level of the disaster. Determine the flash flood hazard area reasonably, and plot the threat area and transfer route on the working base map. Dadi Village, the initial results of the division of dangerous areas are shown in Fig. 1.

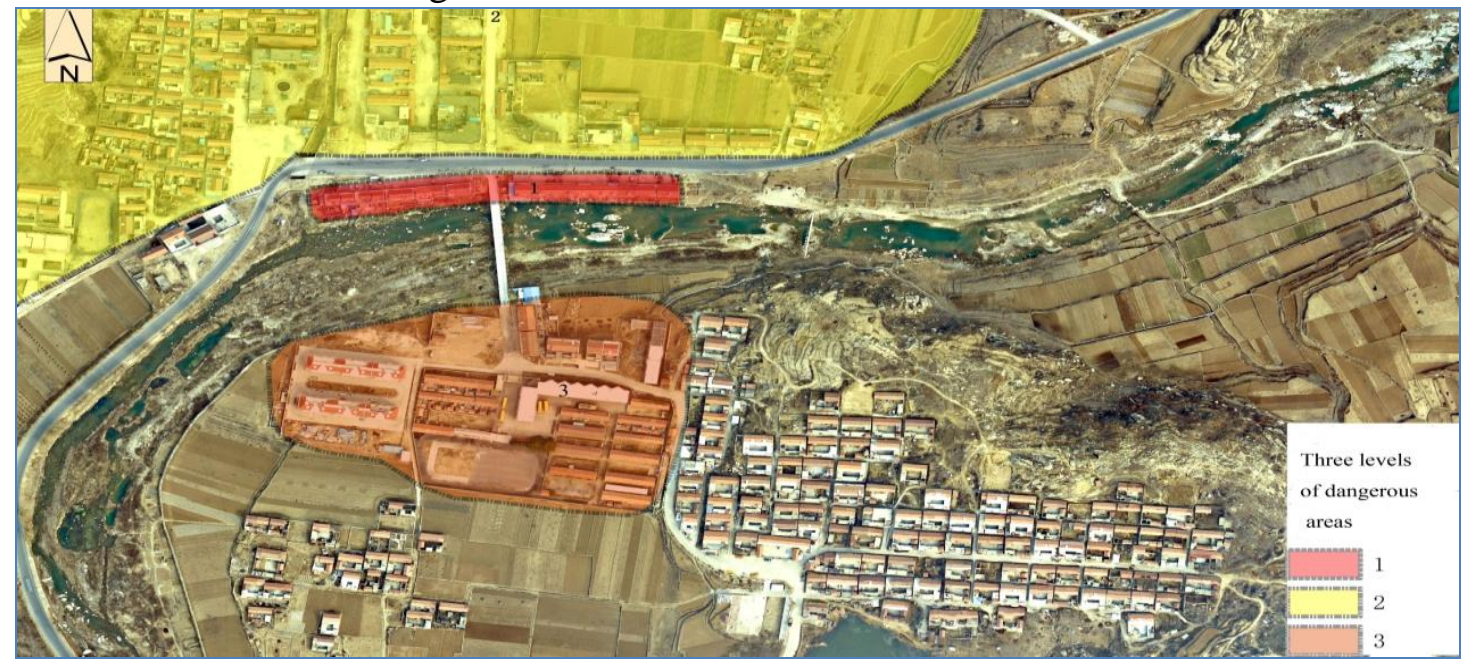

Figure 1. The initial results of the division of dangerous areas 


\section{Summary}

Main Experience. About the business organization, division of labor and coordination. Organize of all participants in the training before the field survey. In theory, be familiar with the background, content, requirements and significance of mountain flood disaster investigation. After a reasonable division of labor, each one clear their own tasks. In the actual survey, from the county, township, along the river village level down, advance contact and coordination to ensure the smooth village.

Special condition investigation and evaluation. In accordance with the field survey steps, after the first understanding of the situation in the village. On the one hand, these small reservoirs, Xiaotangba improve the downstream flood control capacity. On the other hand, because it is located in the upper reaches of the village, and is a mountainous flood control works, in the event of flash floods, it will cause catastrophic accidents. Therefore, the survey of small reservoirs and small dams should be strengthened in the investigation of torrential disaster in small watershed, and the investigation and evaluation methods for such special conditions should be studied. The model can effectively shorten the time of section measurement, and can carry out the province at the same time, greatly improving the field survey efficiency.

Make full use of existing resources. In the first phase of the completion of the construction of flash floods county-level implementation of non-project measures and flash floods census table for the survey and evaluation provide a wealth of information. The original designated small watershed and dangerous villages for the survey to determine the scope of work and determine the villages along the river provides an important reference. Completed in 2008 to complete the revision of the "hydrological calculation manual in Shanxi Province" historical flood survey provides an excellent basis for the hydrological basic data collection. Design rainstorm and flood calculation methods, parameters and their calculation software become practical and efficient analysis and evaluation tool software.

The development of utility software. As a flash flood disaster investigation and evaluation which has been developed and prepared to develop two small tools software. Water level flow curve and flood control evaluation software can complete the analysis and evaluation of the relevant tasks in batches, improve work efficiency.

Carry out pre-study of difficult issues. In 2013, the hydrological bureau of Shanxi Province and Wuhan University studied the calculation of the early warning index from the aspects of hydrological method and hydrodynamic method, and achieved initial results. In 2014, the study continued to focus on the application of distributed hydrological models to the calculation of early-warning indicators for small watersheds in Shanxi Province, and to study the mechanism of production and runoff under special surface conditions.

Recommendations. Overall arrangements, the overall deployment. Make co-ordination arrangements in the completion of the national task of issuing evaluation based on the basis of their own circumstances. Combined with the task assigned by the state and the actual situation in Shanxi Province, We completed all the 114 counties in the province of all survey tasks, and completed the national task analysis of the county assessment of the work in 2014.

The development of work programs and technical rules. In the overall arrangement, based on the investigation and evaluation around the situation, develop realistic programs of work and technical rules, that all tasks have rules to meet the different levels of investigation and evaluation of staff needs.

Carry out special training actively. Mountain torrent disaster investigation and evaluation task is heavy, difficult and demanding.To this end, we must have full technical guidance of professionals. Learning "mountain torrents disaster investigation technical requirements" and "mountain torrent disaster analysis and evaluation of technical requirements", and carry out special training, a comprehensive understanding of the master mountain flood disaster investigation and evaluation of the technical requirements.

Carry out basic research, to solve technical problems for local special problems. For example, study the effect of silt dam construction on the early warning of flood and solve the problem of dam breakage flow calculation ${ }^{[6-10]}$. 


\section{Acknowledgements}

This work was supported by National Natural Science Foundation of China (No.51409119); Project Supported by National Science and Technology Ministry(ID:2015BAB07B03, 2015BAB07B02); Water Conservancy research and Technology Promotion Project of Shandong of China (ID:SDSLKY201404).

\section{References}

[1] National torrential disaster investigation and evaluation project team: Mountain Torrent Disaster Investigation Technology (China Water Power Press, China 2014).

[2] National Torrential Disaster Investigation and Evaluation Project Team: Technical Requirements for Mountain Flood Disaster Assessment and Evaluation (China Water Power Press, China 2014).

[3] Shanxi Provincial Department of Water Resources: Shanxi Province hydrological calculation manual (The Yellow River Water Conservancy Press, China 2010).

[4] Li Changzhi, Sun Dongya: Determination of flood warning index for mountain flood. Advances in Water Science. 23(2012)3, 650-655. (in Chinese)

[5] Zhou Wei, Tang Chuan,Zhou Chunhua: Critical rainfall characteristics for rainfall-induced debris flows in Wenchuan earthquake affected areas. Journal of Hydraulic Engineering. 39(2008)6, 733-738. (in Chinese).

[6] Jiang Jinhong, Shao Liping: Standard of mountain flood warning based on the precipitation observation data. Journal of Hydraulic Engineering, 41(2010)4, 458-463. (in Chinese)

[7] Hapuara.H, Wang. Q. J, Pagano.T.C: A review of advances in flash flood forecasting. Hydrological Processes, 25(2011)18, 2771-2784.

[8] Shamir E, Georgakakos K P, Spencer C: Evaluation of real-time flash flood forecasts for Haiti during the passage of Hur-ricane. Natural Hazards, 67(2013)2: 459-482.

[9] Reeds, Schaake. J,Zhang Z: A distributed hydrologic model and threshold frequency-based method for flash flood forecasting at ungauged locations. Journal of Hydrology,337(2007) 3,402-420.

[10] Smith K T,Austin G L: Nowcasting precipitation: A proposal for a way forward. Journal of Hydrology, 
